\title{
PENGGUNAAN TAWAS CAIR RECOVERY DARI LIMBAH PADAT LUMPUR PDAM KOTA PONTIANAK SEBAGAI KOAGULAN UNTUK PENGOLAHAN AIR BERSIH
}

\author{
Meity Moerdiyanti ${ }^{1}$, Titin Anita Zahara ${ }^{2}$, Dian Rahayu Jati ${ }^{1}$ \\ ${ }^{1}$ Program Studi Teknik Lingkungan Universitas Tanjungpura Pontianak \\ ${ }^{2}$ Program Studi Matematika dan IImu Pengetahuan Alam Universitas Tanjungpura \\ Pontianak \\ email: meity_tekling@yahoo.com
}

\begin{abstract}
ABSTRAK
Limbah padat lumpur (LPL) PDAM dari proses koagulasi yang belum diolah atau dimanfaatkan hingga saat ini langsung dibuang ke Sungai Kapuas dan berpotensi mencemari air sungai. Studi terhadap pemanfaatan kembali aluminium pada LPL PDAM Kota Pontianak sebagai koagulan dilakukan untuk mengolah limbah sehingga dapat digunakan kembali dalam bentuk tawas cair, menentukan kondisi terbaik dan dapat menentukan biaya yang diperlukan untuk recovery dan aplikasinya. Recovery aluminium meliputi pengeringan dan kalsinasi lumpur, pengambilan kembali aluminium dengan metode asidifikasi menggunakan $\mathrm{H}_{2} \mathrm{SO}_{4}$ konsentrasi $10 \mathrm{M}$. Berat kering LPL PDAM yang digunakan sebesar 2 gram, kecepatan aduk $40 \mathrm{rpm}$ selama 120 menit dan pengendapan selama 60 menit. Konsentrasi aluminium yang didapatkan dari tawas cair recovery sebesar 646, 13 ppm atau setara dengan 161,53 mg. Tawas cair recovery diaplikasikan pada proses koagulasi-flokulasi terhadap air baku untuk melihat efektifitas kerja tawas cair. Kondisi terbaik untuk tawas cair yaitu pada dosis $12 \mathrm{mg}$, kecepatan aduk cepat $160 \mathrm{rpm}$ dan kecepatan aduk lambat $20 \mathrm{rpm}$ dengan persen penyisihan kekeruhan sebesar 99,26\%. Biaya yang diperlukan untuk proses recovery dan aplikasi pada tawas cair sebesar Rp 1.188/L.
\end{abstract}

Kata kunci: recovery, tawas cair, koagulasi

\section{ABSTRACT}

Solid waste sludge also called LPL PDAM from coagulation process has not been processed or utilized and directly discharged into the Kapuas River and potentially pollute the river water. Study for recovery of aluminum in LPL PDAM Pontianak as a coagulant for treat waste that can be reused as liquid alum, determine the best conditions and the cost required for recovery and application. Recovery includes drying and calcining aluminum sludge, aluminum retrieval by acidification method using $\mathrm{H}_{2} \mathrm{SO}_{4}$ concentration of $10 \mathrm{M}$. Dry weight LPL taps used by 2 grams, stirring speed of $40 \mathrm{rpm}$ for 120 minutes and sedimentation for 60 minutes. Aluminum concentration obtained from liquid alum recovery was $646,13 \mathrm{ppm}$ or equivalent to $161.53 \mathrm{mg}$. Liquid alum recovery applied to the coagulation-flocculation process of raw water to see the effectiveness of liquid alum and alum commercial. The best conditions for liquid alum at a dose of $12 \mathrm{mg}$, stirring speed $160 \mathrm{rpm}$ fast and slow stirring speed of $20 \mathrm{rpm}$ with a turbidity of 99,26 percent allowance. Costs required for the recovery process and the application of liquid alum at $R p 1,188$ / L.

Keywords : recovery, liquid alum, coagulation

\section{Pendahuluan}

Meningkatnya aktivitas di hulu sungai menyebabkan meningkat pula kekeruhan air Sungai Kapuas, yaitu mencapai 153,5 NTU (PDAM, 2013) sementara batas yang diperbolehkan hanya 5 NTU (Permenkes No. 492 Tahun 2010). Pengolahan yang dilakukan di PDAM Kota Pontianak meliputi pembubuhan koagulan untuk menurunkan kandungan zat organik serta kekeruhan pada air. Koagulan yang digunakan untuk mengolah air di PDAM Kota Pontianak adalah jenis tawas atau alum karena mudah didapat, mudah digunakan dan ekonomis harganya dibanding 
koagulan lain. Namun memiliki kelemahan yaitu menambah jumlah ion-ion $\mathrm{Al}^{3+}$ ke dalam air dan dapat menimbulkan pencemaran.

Menurut Suherman (2003), LPL PDAM tersebut masih mengandung aluminium dalam bentuk $\mathrm{Al}(\mathrm{OH})_{3}$ yang berpotensi sebagai pencemar jika langsung dibuang ke badan air seperti yang terjadi di PDAM Kota Pontianak. Beberapa penelitian telah membuktikan bahwa pengolahan pada LPL PDAM dapat digunakan kembali, diantaranya penelitian tentang pemanfaatan kembali LPL PDAM untuk penjernihan air dari Sungai Martapura dan pengambilan kembali alumina dari LPL PDAM Intan Banjar (Mirwan, 2012).

Lumpur akan selalu dihasilkan di setiap proses pengolahan air, apapun jenis dan bentuk teknologi pengolahan yang digunakan. Semakin besar debit pengolahan pada suatu Instalasi Pengolahan Air Minum (IPAM), maka akan semakin tinggi konsentrasi padatannya, baik padatan kasar (coarse solid), padatan tersuspensi (suspended solid) maupun koloid dan akan makin besar pula lumpurnya. University School of Medicine di Belgrade menerbitkan informasi bahwa minum air dengan aluminium tinggi dan konsentrasi fluoride yang rendah dikaitkan dengan risiko Alzhaimer.

Aluminium hidroksida dalam lumpur dapat larut dalam asam kuat maupun basa kuat. Oleh karena itu, metode perolehan kembali aluminium dengan asam dan basa masih terus dipakai (Boaventura et al., 2000). Adapun faktor-faktor yang mempenagruhi proses perolehan kembali aluminium adalah konsentrasi asam kuat, pengaruh kecepatan dan waktu pengadukan serta massa lumpur kering yang digunakan.

Pada penelitian ini akan dilakukan proses perolehan kembali dengan proses asidifikasi, yaitu salah satu teknik perolehan kembali aluminium di dalam lumpur dengan menggunakan asam kuat yang disertai dengan pengadukan dan pengendapan. Menurut Kurniawan (2009) proses asidifikasi dengan asam kuat bertujuan untuk mengikat kandungan aluminium yang terdapat dalam lumpur sehingga akan dihasilkan cairan atau filtrat yang kaya akan aluminium. Melalui proses asidifikasi menggunakan asam kuat diharapkan aluminium dapat diperoleh kembali dari $\mathrm{Al}(\mathrm{OH})_{3}$.

\section{Metode Penelitian}

Alat-alat yang digunakan pada penelitian ini adalah alat-alat gelas laboratorium, jartest apparatus, kertas saring, pipet volumetrik, $\mathrm{pH}$ meter, shaker, spektrofotometer serapan atom (SSA), tanur, timbangan analitik dan turbidimeter.

Bahan-bahan yang digunakan pada penelitian ini adalah akuades, air baku (air Sungai Kapuas), asam sulfat $\left(\mathrm{H}_{2} \mathrm{SO}_{4}\right)$, Limbah Padat Lumpur keluaran IPAM IV di PDAM Kota Pontianak, $\mathrm{NaOH}$ dan tawas komersil.

Sampel kering LPL PDAM siap pakai dikalsinasi dalam tanur pada suhu $500^{\circ} \mathrm{C}$ selama 2 jam. Kemudian diambil sebanyak 2 gram dan direaksikan dengan larutan $\mathrm{H}_{2} \mathrm{SO}_{4} 10 \mathrm{M}$ dengan kecepatan aduk $40 \mathrm{rpm}$ selama 120 menit dan didiamkan selama 60 menit.

\section{Preparasi Sampel Lumpur PDAM}

Sampel limbah lumpur (sludge) dari bak sedimentasi Instalasi Pengolahan Air Minum PDAM Kota Pontianak diendapkan selama 1-2 jam untuk memisahkan lumpur dan air yang lebih jernih. Lapisan air di bagian atas kemudian dibuang dan hanya menyisakan lumpur padat. Lumpur padat dituangkan pada pelat-pelat tipis dan dikeringkan dengan sinar matahari selama 17 hari. Sebanyak 3 gram sampel dianalisis kandungan aluminiumnya menggunakan SSA (SNI 06-6989.36-2005). Sampel hasil pengeringan dikalsinasi dalam tanur pada suhu $500^{\circ} \mathrm{C}$ selama 2 jam (Boaventura et al., 2000). Sampel yang telah dikalsinasi kemudian diperiksa kandungan zat organik dan aluminiumnya dengan spektrofotometer serapan atom (SNI 066989.36-2005). 
Disiapkan satu buah botol $250 \mathrm{~mL}$ dan dimasukkan 2 gram masa kering yang telah diturunkan kandungan zat organiknya. Berikutnya ditambahkan larutan $\mathrm{H}_{2} \mathrm{SO}_{4} 10 \mathrm{M}$ ke dalam botol. Semua botol diaduk pada kecepatan $40 \mathrm{rpm}$ selama 120 menit dan didiamkan selama 60 menit, lalu disaring (Boaventura et al., 2000 dan Kurniawan, 2009). Kadar aluminium dalam filtrat yang diperoleh dianalisis menggunakan SSA (SNI 06-6989.36-2005).

\section{Penentuan Massa Tawas Cair Efektif}

Aplikasi pada tawas cair dilakukan dengan variasi massa (a) sebesar 0,$24 ; 0,74 ; 1,2 ; 2,5$; 4,9; 7,4; 9,9; 12,0 dan 15,0 mg. Pengadukan cepat $100 \mathrm{rpm}$ selama 1 menit dan dilanjutkan pengadukan lambat $20 \mathrm{rpm}$ selama 15 menit. Kemudian diendapkan selama 60 menit dan dianalisa kekeruhan pada air olahan.

\section{Penentuan Pengadukan Cepat Efektif}

Aplikasi pada tawas cair dilakukan dengan menggunakan massa efektif (a). Pengadukan cepat (b) 100, 120, 140 dan $160 \mathrm{rpm}$ selama 1 menit dan dilanjutkan pengadukan lambat 20 rpm selama 15 menit. Kemudian diendapkan selama 60 menit dan dianalisa kekeruhan pada air olahan dengan turbidimeter.

\section{Penentuan Pengadukan Lambat Efektif}

Aplikasi pada tawas cair dilakukan dengan menggunakan massa efektif (a). Pengadukan cepat menggunakan kecepatan efektif (b) selama 1 menit dan dilanjutkan pengadukan lambat (c) 20, 40, 60 dan $80 \mathrm{rpm}$ selama 15 menit. Kemudian diendapkan selama 60 menit dan dianalisa kekeruhan dengan turbidimeter.

\section{Hasil dan Pembahasan \\ Recovery Tawas Cair}

Kandungan karbon organik total (KOT) pada LPL PDAM akan menghambat aluminium untuk digunakan kembali karena aluminium tersebut harusnya dapat mengikat kandungan bahan organik penyebab kekeruhan pada air baku. КОT ini harus diturunkan agar tidak mengganggu proses perolehan kembali aluminium, namun salah satu penyusun dari zat organik adalah asam fulvat yang sifatnya larut dalam asam dan dapat mengganggu kerja dari koagulan ini saat direaksikan dengan air baku (Boaventura et al., 2000). Untuk mempermudah proses pengambilan kembali aluminium dari lumpur kering ini dilakukan proses pemanasan pada suhu tinggi atau kalsinasi pada suhu $500^{\circ} \mathrm{C}$ di dalam tanur selama 2 jam yang bertujuan menurunkan kandungan KOT dalam lumpur.

Kalsinasi dilakukan pada suhu $500^{\circ} \mathrm{C}$ karena aluminium memiliki titik leleh hingga $660^{\circ} \mathrm{C}$ (Sumanto, 1994), sehingga aluminium tidak rusak karena pengaruh suhu tinggi yang masih berada di bawah titik lelehnya. Hal ini dapat dilihat dari hasil pengujian kandungan aluminium pada lumpur sebelum dan setelah kalsinasi dengan Spektrofotometer Serapan Atom (SSA). Kandungan lumpur kering LPL PDAM Kota Pontianak adalah sebagai berikut:

Tabel 1. Kandungan LPL PDAM Kota Pontianak

\begin{tabular}{|c|l|c|c|c|c|}
\hline \multirow{2}{*}{ No } & \multirow{2}{*}{ Jenis Sampel } & \multicolumn{2}{|c|}{$\begin{array}{c}\text { Parameter } \\
\text { Analisis }\end{array}$} & \multicolumn{2}{|c|}{ Metode } \\
\cline { 3 - 6 } & & \multicolumn{2}{|c|}{ Al } & KOT & \multicolumn{2}{c|}{} \\
\cline { 3 - 6 } & & \multicolumn{2}{|c}{$(\%)$} & Al & KOT \\
\hline 1 & Lumpur Kering & 98,69 & 6,36 & SSA & Walkley and Black \\
\hline 2 & Lumpur Kalsinasi & 97,44 & 0,28 & SSA & Walkley and Black \\
\hline
\end{tabular}


Dari hasil tersebut diketahui bahwa penyusutan kandungan aluminium hanya terjadi sebesar 1,25\% dari jumlah aluminium awal pada lumpur. Lumpur hasil kalsinasi tersebut kemudian di reakasikan dengan asam sulfat pekat. Kondisi optimum untuk recovery tawas cair adalah sebagai berikut: masa lumpur kering siap pakai seberat 2 gram dan direaksikan dengan larutan $\mathrm{H}_{2} \mathrm{SO}_{4} 10 \mathrm{M}$, yang kemudian diaduk pada kecepatan $40 \mathrm{rpm}$ selama 120 menit dan didiamkan selama 60 menit, lalu disaring (Boaventura et al., 2000 dalam Kurniawan, 2009). Berikut adalah reaksi kimia dari proses asidifikasi di dalam lumpur (Goldman et al., 1975).

$2 \mathrm{Al}(\mathrm{OH})_{3}+\mathrm{XH}_{2} \mathrm{O}+3 \mathrm{H}_{2} \mathrm{SO}_{4} \rightarrow \mathrm{Al}_{2}\left(\mathrm{SO}_{4}\right)_{3}+(6+\mathrm{x}) \mathrm{H}_{2} \mathrm{O}$

Filtrat berupa tawas cair kemudian di uji dengan SSA. Hasil uji dari filtrat dengan SSA diketahui konsentrasi aluminium sebesar $646,13 \mathrm{ppm}$. Efektifitas perolehan kembali aluminium dalam penelitian ini yaitu sebesar $58,56 \%$. Hal ini sesuai dengan penelitian yang dilakukan oleh Boaventura et al. (2000) bahwa dalam kondisi asam dihasilkan aluminium sebesar 56,3\% hingga 58,9\%. Pembuatan tawas cair dari lempung lokal Paminggir dapat menghasilkan perolehan kembali aluminium hingga 70,36\% (Diana, 2009), karena pada proses reaksi dengan asam sulfat diberikan perlakuan pemanasan. Menurut Keenan (1986) dengan adanya temperatur lebih tinggi, maka molekul-molekul akan bergerak lebih cepat dan menyebabkan benturan antar partikel lebih sering terjadi. Sehingga energi untuk bereaksi lebih cepat terpenuhi, dan reaksi antara asam sulfat dan lempung lebih cepat terjadi dan memperoleh lebih banyak aluminium.

\section{Efektifitas Penggunaan Tawas Cair}

\section{- Pengaruh Massa Tawas Cair}

Filtrat atau tawas cair ini kemudian diaplikasikan pada air baku untuk menurunkan kekeruhan yang salah satunya disebabkan oleh partikel koloid. Massa tawas cair yang digunakan adalah sebesar 0,$24 ; 0,74 ; 1,2 ; 2,5 ; 4,9 ; 7,4 ; 9,9 ; 12,0$ dan 15,0 mg. Variasi massa dilakukan untuk mengetahui kadar tawas cair yang paling efektif untuk menurunkan kekeruhan pada air baku dan mengetahui pengaruh penambahan tawas cair terhadap proses koagulasi yang terjadi pada air. Prosedur analisis data menggunakan turbidimeter dengan satuan NTU (Nephelometric Turbidity Units) yang mengacu pada SNI 06-6989.25-2005. Hasil pengujian kekeruhan pada air olahan dengan tawas cair ditampilkan pada Gambar 1.

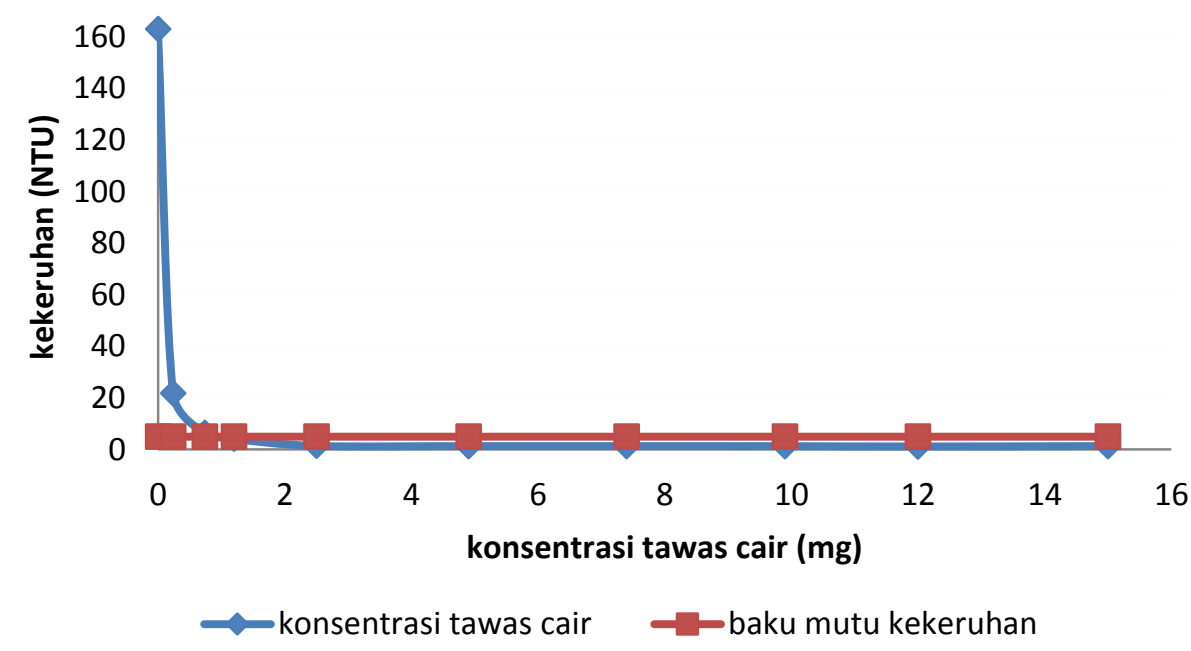

Gambar 1. Pengaruh Variasi Konsentrasi Tawas Cair terhadap Kekeruhan 
Gambar 1. menunjukkan penambahan tawas cair akan cenderung menurunkan kekeruhan dalam air. Tawas cair efektif pada konsentrasi $12 \mathrm{mg}$ dan dapat menurunkan kekeruhan ratarata sebesar 1,2 NTU. Aplikasi tawas cair dari konsentrasi 1,2 - $15 \mathrm{mg}$ dapat menurunkan kekeruhan hingga di bawah baku mutu, karena kandungan $\mathrm{Al}^{3+}$ pada tawas cair cukup untuk mendestabilisasi koloid. Berdasarkan data kekeruhan yang ada, dapat diketahui efektivitasnya melalui persamaan berikut.

$$
\% \text { efektivitas }(\% \Delta)=\frac{T_{1}-T_{2}}{T_{1}} \times 100 \%
$$

Hasil perhitungan persen efektivitas ditunjukkan pada Gambar $\mathbf{2}$ berikut.

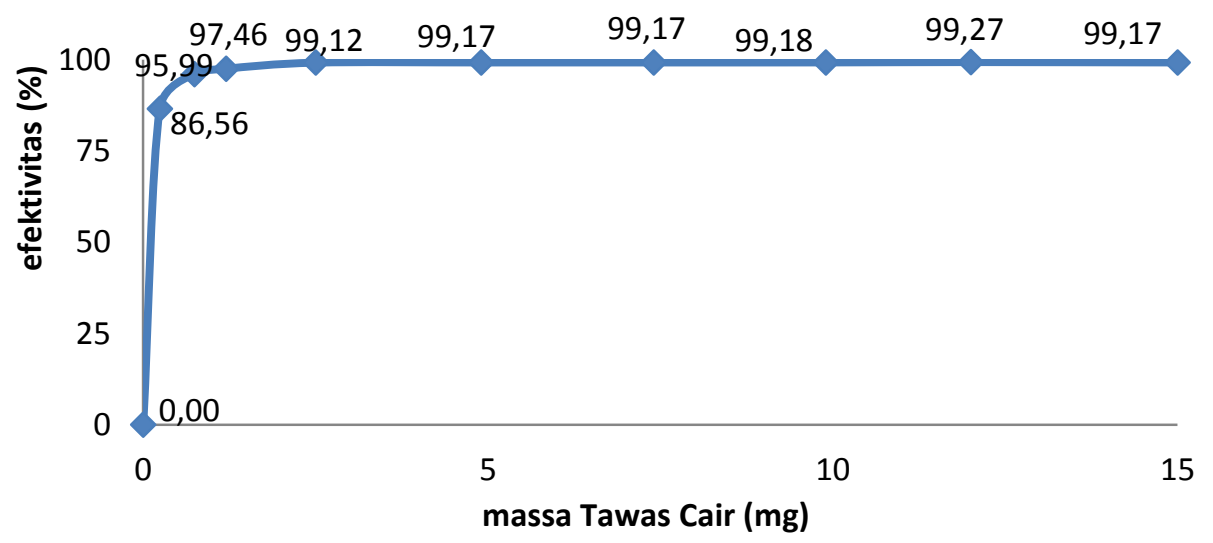

Gambar 2. Grafik Hubungan Antara Konsentrasi Tawas Cair Dan Efektivitas Penurunan Kekeruhan

Pada Gambar 2 diketahui penambahan tawas cair sebanyak $15 \mathrm{mg}$ menyebabkan kekeruhan kembali meningkat. Hal ini dikarenakan adsorpsi kation yang berlebih pada permukan partikel koloid yang berumatan negatif dengan muatan berlawanan $\mathrm{Al}^{3+}$ dari aluminium sulfat. Sehingga terjadi deflokulasi pada partikel koloid yang menyebabkan partikel koloid menjadi bentuk yang stabil sebagai akibat dari gaya tolak-menolak antar partikel yang bermuatan sejenis (Ravina, 1993). Menurut Reynolds (1982) penambahan alum di atas dosis menyebabkan ion positif dari aluminium terlalu banyak dan koloid yang telah mengalami netralisasi sempurna (mencapai titik isoelektrik) menjadi bermuatan kembali dan ikut terdispersi kembali dalam air, akibatnya kekeruhan akan kembali meningkat.

Dari pengujian air baku dengan $\mathrm{pH}$ meter diketahui $\mathrm{pH}$ air baku sebesar 7,8 dan termasuk $\mathrm{pH}$ normal karena berada dalam rentang 6-9 sesuai dalam Permenkes No. 492/MENKES/PER/IV/2010. Aplikasi tawas cair menyebabkan terjadi penurunan pH pada air baku yang telah diolah, seperti yang ditunjukkan pada Gambar 3. 


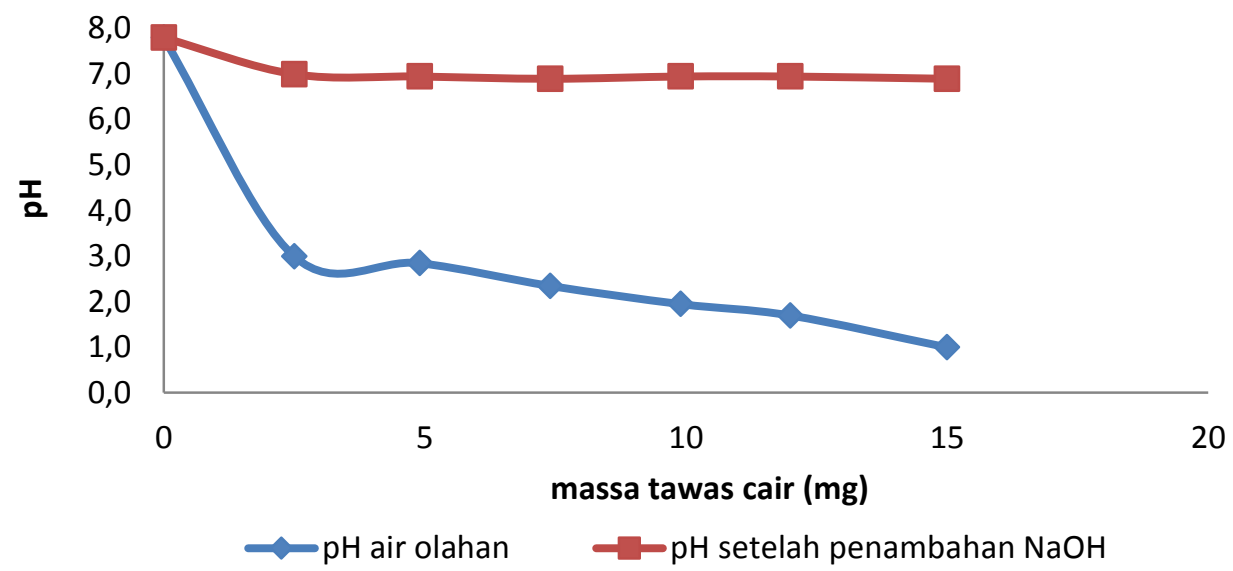

Gambar 3. Pengaruh pH pada Air Olahan dengan Tawas Cair

Menurut Shammas (2005) penurunan pH ini disebabkan oleh tawas cair yang memiliki sifat asam dan menyebabkan peningkatan kadar sulfur. Sehingga penambahan koagulan berbanding lurus dengan penurunan $\mathrm{pH}$ karena adanya reaksi sebagai berikut (Hanum,2002).

$\mathrm{Al}_{2}\left(\mathrm{SO}_{4}\right)_{3} \longrightarrow 2 \mathrm{Al}^{+3}+3\left(\mathrm{SO}_{4}\right)^{-2}$

Di dalam air akan terionisasi menjadi:

$\mathrm{H}_{2} \mathrm{O} \longrightarrow \mathrm{H}^{+}+\mathrm{OH}^{-}$

$2 \mathrm{Al}^{+3}+6 \mathrm{OH}^{-} \longrightarrow 2 \mathrm{Al}(\mathrm{OH})_{3}$

Selain itu ion sulfat akan bereaksi dengan ion hidrogen untuk membenruk asam:

$3\left(\mathrm{SO}_{4}\right)^{2-}+6 \mathrm{H}^{+} \longrightarrow 3 \mathrm{H}_{2} \mathrm{SO}_{4}$

pH kerja tawas terletak di antara 5,8 - 7,4 karena aluminium hidroksida relatif tidak larut pada rentang tersebut (Amir, 2012). Sehingga pada penelitian ini ditambahkan $\mathrm{NaOH}$ hingga alkalinitas pada air olahan tersebut sesuai dalam rentang $\mathrm{pH}$ tawas agar aluminium hidroksida yang terbentuk dapat diendapkan dan tidak larut kembali.

Sebagai data tambahan dilakukan pula pengujian kandungan bahan organik pada air hasil aplikasi tawas cair. Kandungan zat organik pada air baku yaitu sebesar 30,02 mg/L. Setelah proses koagulasi dengan tawas cair kandungan zat organik turun hingga 6,32 mg/L. Baku mutu untuk kandungan zat organik di air adalah $10 \mathrm{mg} / \mathrm{L}$. Sehingga tawas cair pada kondisi optimum tidak hanya mampu menurunkan kekeruhan tapi juga kandungan zat organik di air.

Penurunan zat organik terjadi karena kelompok humin (koloid hidrofilik) yang bermuatan negatif mengalami netralisasi oleh ion $\mathrm{Al}^{3+}$ dalam bentuk larutan alum pada rentang $\mathrm{pH}$ kerja tawas. Menurut Spark dkk (1997) pada $\mathrm{pH}$ yang relatif tinggi (konsentrasi $\mathrm{H}^{+}$rendah) akan meningkatkan konsentrasi -COO- yang dapat berfungsi sebagai ligan pada asam humat di air. Ligan ini akan berikatan dengan ion logam (ion pusat) yaitu $\mathrm{Al}^{3+}$ pada tawas, sehingga partikel koloid asam humat dapat diendapkan.

\section{- Pengaruh Variasi Kecepatan Aduk Cepat}

Pada penelitian ini digunakan variasi kecepatan untuk mengetahui pengaruh kecepatan pengadukan cepat terhadap proses koagulasi. Variasi kecepatan yang digunakan adalah 100, 120, 140 dan $160 \mathrm{rpm}$ selama 1 menit dan dilanjutkan pengadukan lambat yaitu $20 \mathrm{rpm}$ selama 15 menit menggunakan konsentrasi terbaik sebesar $12 \mathrm{mg}$. Hasil optimasi ditunjukkan oleh Gambar 4. 


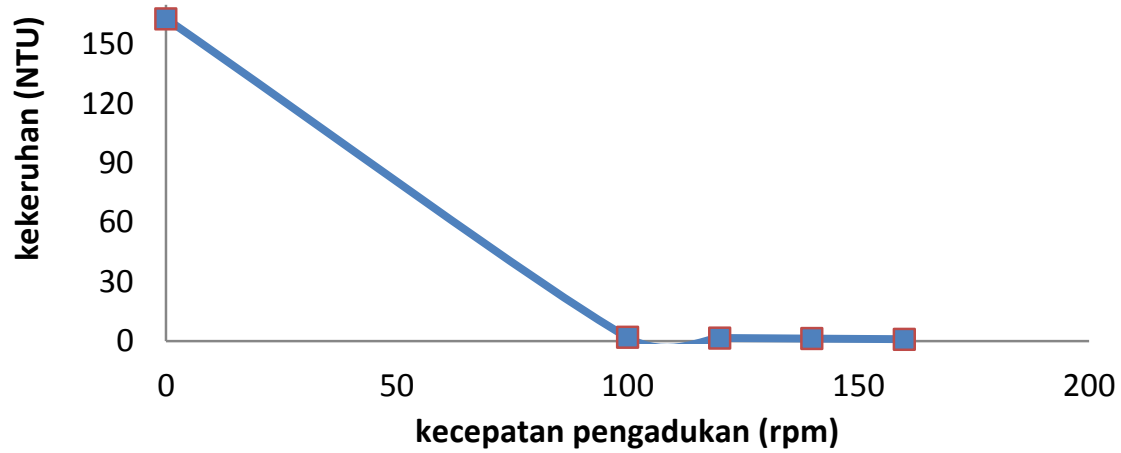

Gambar 4 Pengaruh Kecepatan Aduk Cepat terhadap Penurunan Kekeruhan

Gambar 4 menunjukkan bahwa semakin tinggi kecepatan aduk pada proses pengadukan cepat (koagulasi) maka kekeruhan akan semakin rendah. Karena pada proses ini diharapkan air dapat bergolak (turbulen) agar koagulan dapat terdistribusi merata yang dilanjutkan dengan proses adsorpsi koagulan oleh koloid dan terbentuk jembatan antar partikel. Sehingga terjadi penurunan surface potential melalui adosrpsi dan terjadi netralisasi muatan karena adanya penurunan potensial zeta ke tingkat dimana gaya tarik Van der Walls meningkat (Reynolds, 1982). Sehingga semakin cepat pengadukan distribusi koagulan akan semakin cepat dan merata ke seluruh air, maka pada saat proses pengadukan lambat terjadi pembentukan flok lebih mudah terjadi.

Semakin meningkatnya kecepatan aduk cepat, jumlah flok yang berhasil diendapkan pun terlihat semakin banyak. Hal ini disebabkan karena adanya pembentukan jembatan antar partikel dengan bantuan energi adukan sehingga jumlah partikel koloid yang dapat berikatan membentuk flok dan endapan yang terbentuk semakin banyak. Presipitasi dari koagulan akan menyapu lebih banyak koloid seiring bertambahnya kecepatan hingga ukuran flok yang terbentuk lebih besar dan lebih cepat mengendap. Kecepatan pengadukan cepat terbaik untuk aplikasi tawas cair pada kecepatan 160 rpm.

\section{- Pengaruh Variasi Kecepatan Aduk Lambat}

Tawas cair diaplikasikan pada air baku dengan variasi pada pengadukan lambat yaitu, 20, 40, 60 dan $80 \mathrm{rpm}$ untuk mengetahui pengaruh variasi pengadukan lambat terhadap proses koagulasi. Hasil optimasi pengadukan lambat pada aplikasi tawas cair dapat dilihat pada Gambar 5.

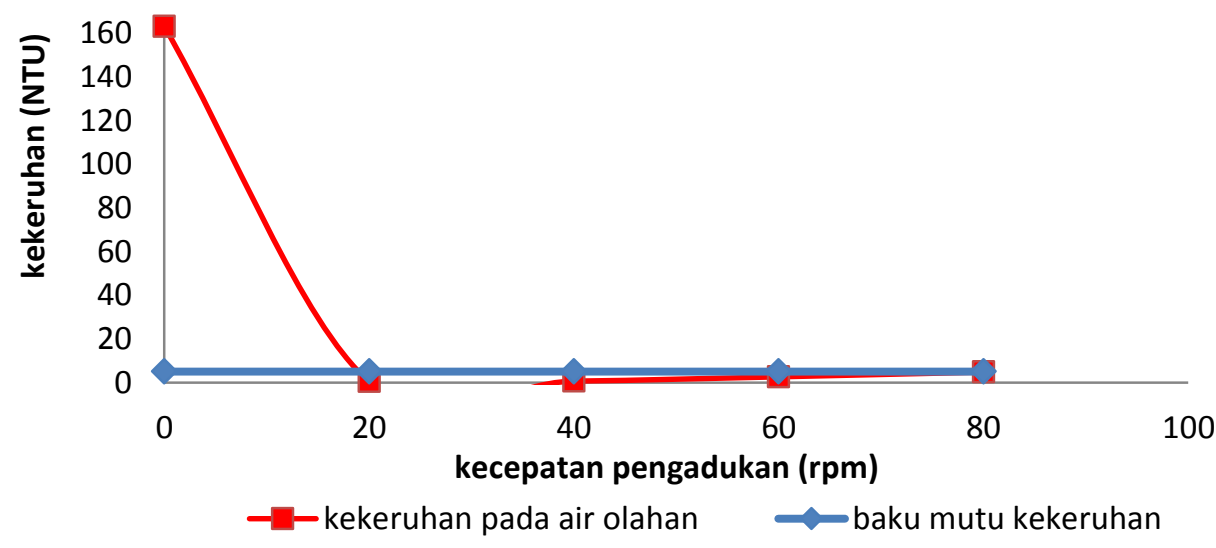

Gambar 5. Pengaruh Kecepatan Aduk Lambat terhadap Penurunan Kekeruhan 
Dari Gambar 5 diketahui bahwa semakin rendah kecepatan pada pengadukan lambat maka akan semakin rendah pula nilai kekeruhan di air. Karena pada proses flokulasi energi tambahan berupa adukan yang dibutuhkan tidak terlalu besar. Kecepatan pengadukan lambat terbaik untuk aplikasi tawas cair di penelitian ini pada kecepatan $20 \mathrm{rpm}$.

Menurut Reynolds (1982) pengadukan lambat optimum akan menghasilkan jarak antar partikel yang paling dekat untuk menghasilkan kontak, tumbukan antar partikel paling sering terjadi sehingga dihasilkan flok dengan ukuran terbesar dan jumlah terbanyak, sehingga penurunan kekeruhan maksimum. Namun saat ukuran partikel sudah maksimum dan ideal untuk mengendap, penambahan kecepatan aduk akan menurunkan efektifitas koagulasi karena flok partikel terlarut yang sudah jenuh akan pecah kembali. Thermal motion atau yang sering dikenal sebagai Brownian motion juga berperan dalam proses tersebut (Marsono,1997).

\section{Analisa Biaya}

Pada penelitian ini dilakukan analisa terhadap biaya yang digunakan pada recovery dan aplikasi tawas cair atau tawas komersil. Dosis $12 \mathrm{mg}$ adalah konsentrasi terbaik yang digunakan dalam analisa biaya ini, karena dapat menurunkan kadar kekeruhan hingga dibawah baku mutu (5 NTU), yaitu 1,2 NTU. Daftar harga bahan yang dibutuhkan dalam analisa ini dapat dilihat pada Tabel 3, sementara hasil perhitungan biaya pada proses recovery dapat dilihat pada Tabel 4.

Tabel 3. Daftar Harga Bahan-Bahan yang Digunakan pada Recovery dan Aplikasi Tawas Cair

\begin{tabular}{|c|c|c|c|}
\hline No & Jenis Bahan & Harga Pasaran & Harga Per satuan \\
\hline 1. & Akuades & Rp 2000/liter & Rp $\quad 2000 / L$ \\
\hline 2. & $\mathrm{H}_{2} \mathrm{SO}_{4} 98 \%$ & Rp $310.000 / 20 \mathrm{~L}$ & Rp 15.500/L \\
\hline 3. & $\mathrm{NaOH}$ & Rp $\quad 22.000 / K g$ & $\operatorname{Rp} 22.000 / \mathrm{Kg}$ \\
\hline
\end{tabular}

Tabel 4. Hasil Analisa Ekonomi Proses Recovery Tawas Cair

\begin{tabular}{|c|c|c|r|r|}
\hline \multicolumn{1}{|c|}{ Proses } & $\begin{array}{c}\text { Bahan yang } \\
\text { Digunakan }\end{array}$ & Banyak digunakan & $\begin{array}{c}\text { Harga } \\
\text { Satuan }\end{array}$ & Jumlah \\
\hline \multirow{2}{*}{ Recovery } & $\mathrm{H}_{2} \mathrm{SO}_{4}$ & $0,14 \mathrm{~L}$ & 15.000 & 2.170 \\
\cline { 2 - 5 } & Akuades & $0,11 \mathrm{~L}$ & 2.000 & 220 \\
\hline Jumlah & \multicolumn{3}{|l|}{} & 2.390 \\
\hline
\end{tabular}

Recovery tawas cair menggunakan asam sulfat pekat dengan konsentrasi $10 \mathrm{M}$. Volume tawas cair yang dibuat adalah sebanyak 0,25 L, (asam sulfat sebanyak 0,14 L dan akuades sebanyak $0,11 \mathrm{~L}$ ). Perhitungan biaya aplikasi tawas cair adalah sebagai berikut:

- Biaya recovery tawas cair dengan volume $250 \mathrm{~mL}$ adalah $\mathrm{Rp} 2.390$

- Dalam tawas cair terdapat Al dengan konsentrasi $646,13 \mathrm{ppm}=161,53 \mathrm{mg}$.

Sehingga biaya recovery untuk tiap $1 \mathrm{mg}$ adalah $\mathrm{Rp} 14,8$

- Banyaknya tawas yang digunakan adalah $12 \mathrm{mg}$ dalam $250 \mathrm{ml}$ air baku. Sehingga biaya recovery untuk dosis $12 \mathrm{mg}$ tawas adalah:

- $12 \mathrm{mg} \times \mathrm{Rp} 14,8 / \mathrm{mg}=\mathrm{Rp} 178$

- $\mathrm{NaOH}(2 \mathrm{M})$ yang ditambahkan untuk pengolahan air dengan dosis tawas $12,5 \mathrm{mg}$ adalah sebanyak: $67,5 \mathrm{ml}=5,4$ gram $=0,0054 \mathrm{~kg}$

○ $\quad 0,0054 \mathrm{~kg} \times \mathrm{Rp} 22.000=\operatorname{Rp} 119$

Total biaya yang diperlukan untuk aplikasi tawas cair untuk dosis tawas $12,5 \mathrm{mg}$ dan air yang diolah sebanyak $250 \mathrm{~mL}(0,25 \mathrm{~L})$ adalah:

- Biaya tawas cair + biaya $\mathrm{NaOH}=\mathrm{Rp} 178+\mathrm{Rp} 119=\mathrm{Rp} 297$ 
- Biaya aplikasi tawas cair untuk $1 \mathrm{~L}$ air baku: Rp 1.188

Dari hasil perhitungan didapatkan bahwa recovery dan aplikasi pada tawas cair untuk mengolah air berdasarkan penelitian yang telah dilakukan, memerlukan biaya sebesar $\mathrm{Rp}$ $1.188 / \mathrm{L}$.

\section{Kesimpulan dan Saran Kesimpulan}

Tawas cair hasil recovery LPL PDAM dapat digunakan sebagai koagulan untuk menurunkan kekeruhan dalam proses pengolahan air bersih dengan efisiensi penyisihan kekeruhan pada kondisi terbaik sebesar 99,72\% pada massa $12 \mathrm{mg}$, kecepatan aduk cepat $160 \mathrm{rpm}$ dan kecepatan aduk lambat $20 \mathrm{rpm}$. Sementara biaya yang diperlukan untuk recovery dan aplikasi tawas cair sebesar Rp 1.188/L.

\section{$\underline{\text { Saran }}$}

Penelitian ini masih dapat dilanjutkan dengan pengembangan studi untuk menemukan metode recovery aluminium sebagai tawas cair dari LPL PDAM Kota Pontianak dengan biaya yang lebih rendah atau aplikasi lainnya dari recovery aluminium untuk mengatasi masalah buangan lumpur yang dihasilkan.

\section{Ucapan Terima Kasih}

Dalam penelitian dan penulisan jurnal ini penulis mengucapkan terima kasih kepada Ibu Titin Anita Zahara, S.Si, M.Si dan Ibu Dian Rahayu Jati, ST., M.Si selaku dosen pembimbing. Staf PDAM Tirta Khatulistiwa Kota Pontianak. Staff Laboratorium Lingkungan Fakultas Teknik, Laboratorium Kimia Fakultas Matematika dan Ilmu Pengetahuan Alam, Laboratorium Kimia dan Kesuburan Tanah serta Laboratorium Kualitas Tanah, Air dan Lingkungan Universitas Tnajungpura Pontianak. Serta semua pihak yang terlibat dalam penelitian ini yang tidak dapat disebutkan satu per satu.

\section{Daftar Pustaka}

Amir, Rizal dan J.N. Isnaniawardhana. 2012. Penentuan Dosis Optimum Alumunium Sulfat dalam Pengolahan Air Sungai Cileuleur Kota Ciamis dan Pemanfaatan Resirkulasi Lumpur dengan Parameter pH, Warna, Kekeruhan dan TSS. Bandung: J Institut Teknologi Bandung.

Boaventura, A.R.; Duarte, A.S and Almeida, M.F., 2000, Alumunium Recovery From Water Treatment Sludge, International Conference Water Supply and Water Quality.

Diana, R.M. 2009. Studi Awal Pemanfaatan Lempung Lokal Pamnggir sebagai Koagulan Cair. Jurnal ITB: Bandung.

Goldman, M.L and Watson, F. 1975. Feasibility of Alum Sludge Reclamation. Washington Technical Institute. Washington D.C. Final Report Project No. A-001-DC.

Hanum, F. 2002. Proses Pengolahan Air Sungai untuk Keperluan Air Minum. USU Digital Library.

Keenan, Charles W. 1986. Ilmu Kimia untuk Universitas. Erlangga: Jakarta.

Kurniawan, T.W. 2009. Efektivitas Campuran Alumunium Hasil Perolehan Kembali dari Lumpur Padat Pengoalahan Air dengan Besi (III) Klorida sebagai Koagulan. (skripsi).

Marsono, B.D. 1997. Unit Operasi. Media Informasi Alumni ITS: Surabaya.

Mirwan, dkk. 2011. Studi Pengambilan Kembali Alumina dari Limbah Padat Lumpur Perusahaan Daerah Air Minum (PDAM) Intan Banjar. J. Universitas Lambung Mangkurat.

PDAM Kota Pontianak. 2013. Data Kualitas Air Baku Tahun 2013.

Peraturan Menteri Kesehatan Republik Indonesia No: 492/MENKES/PER/IV/2010 Tentang Persyaratan Kualitas Air Minum. 
Ravina, L. 1993. Everything You Want to Know About Coagulation and Floculation. ZetaMeter Inc: Virginia.

Reynolds, T.D and Richards, P.A. 1982. Unit Operations and Process in Environmental Engineering. Texas A\&M Universitas California.

Shammas, Nazih K. 2005. Physicochemical Treatment Processes. Human Press: Lenox.

Spark, K.M., Wells, J.D., and Johnson, B.B. 1994. The Interaction of Humic Acid with Heavy Metals. Auts. Journal Soil.

Standar Nasional Indonesia (SNI) 06-6989.36-2005. Cara Uji Kadar Alumunium (Al) dengan Spektrofotometri Serapan Atom (SSA) secara tungku Karbon

Suherman, B. 2003, "Upaya Minimalisasi Kebutuhan Koagulan di PDAM" Seminar Nasional Teknik Kimia Indonesia Bersama dengan Seminar Nasional Soehadi Reksowardjojo. Intitut Teknologi Bandung dan Fundamental \& Aplikasi Teknik Kimia 2003 Institut Teknologi Sepuluh Nopember Surabaya, Yogyakarta tanggal 16 - 17 September 2003. 